\title{
Choriocarcinoma with uterine rupture presenting as acute haemoperitoneum and shock
}

\section{Mamour Gueye*, Mame Diarra Ndiaye Gueye, Ousmane Thiam, Youssou Toure, Mor Cisse, Mouhamadou Wade, Aliou Diouf, Magatte Mbaye, Jean Charles Moreau}

\begin{abstract}
Department of Obstetrics and Gynecology, Aristide Le Dantec Teaching Hospital, Pasteur Avenue, Cheikh Anta Diop University, Dakar, Senegal
\end{abstract}

Received: 25 December 2016

Accepted: 31 January 2017

\section{*Correspondence: \\ Dr. Mamour Gueye, \\ E-mail: mamourmb@yahoo.fr}

Copyright: (c) the author(s), publisher and licensee Medip Academy. This is an open-access article distributed under the terms of the Creative Commons Attribution Non-Commercial License, which permits unrestricted non-commercial use, distribution, and reproduction in any medium, provided the original work is properly cited.

\begin{abstract}
Choriocarcinoma is a rare neoplasm and a malignant form of gestational trophoblastic disease. Invasive mole may perforate uterus through the myometrium resulting in uterine perforation and intraperitoneal bleeding. But uterine perforation due to choriocarcinoma is rare. We present a case of a young woman who presented 1 year after uterine evacuation of a molar pregnancy with invasive choriocarcinoma complicated by a uterine rupture and haemoperitoneum.
\end{abstract}

Keywords: Choriocarcinoma, Haemoperitoneum, Uterine rupture

\section{INTRODUCTION}

Gestational trophoblastic disease (GTD) encompasses a spectrum of pregnancy-related disorders that includes benign, pre-malignant disorders (complete and partial hydatidiform mole), and persistent, malignant disorders (invasive mole, choriocarcinoma, placental site trophoblastic tumour and epithelial trophoblastic tumour). Gestational trophoblastic neoplasia (GTN) is a term used for the persistent/malignant disorders. ${ }^{1}$

Half a century ago, before the introduction of chemotherapy in the management of GTN, mortality rates associated with invasive moles reached $15 \%$, more frequently due to haemorrhage, sepsis, embolic phenomena or surgical complications. In the presence of metastases, choriocarcinoma had a mortality rate of $100 \%$, and of about $60 \%$ when hysterectomy was performed to treat apparent non-metastatic disease. Currently, cure rates are greater than $90 \%$ even in the case of widespread metastatic disease. ${ }^{2}$ It can present with a wide variety of symptoms depending on the site of metastasis or the extent of invasive growth, but this disease process is very rarely documented in the emergency medicine literature.

We present a case of a young woman who presented one year after uterine evacuation of a molar pregnancy with invasive choriocarcinoma complicated by a uterine rupture and haemoperitoneum.

\section{CASE REPORT}

A 25-year-old female, presented to our department with complaints of acute abdominal pain of 4 days duration associated with vaginal bleeding. She had history of missed abortion one year ago. On examination, she was pale, hypotensive and had tenderness all over her abdomen. On bimanual pelvic examination, the uterus was soft and bulky, fullness and tenderness could be elicited through the posterior fornix. Following resuscitative measures, she was taken up for an emergency laparotomy with a suspicion of haemoperitoneum. Abdomen was opened and 2 litres of 
haemoperitoneum were evacuated. There was a profuse haemorrhage from the uterine fundus and the perforated area resembled trophoblastic tissue. The uterus was soft and enlarged to a size of 20 weeks pregnancy. The intestines were joined together in trophoblastic tissue (Figure 1). We conducted a careful dissection with a visceral surgeon and have achieved total hysterectomy. Haemostasis was good and we realized the parietal closure.

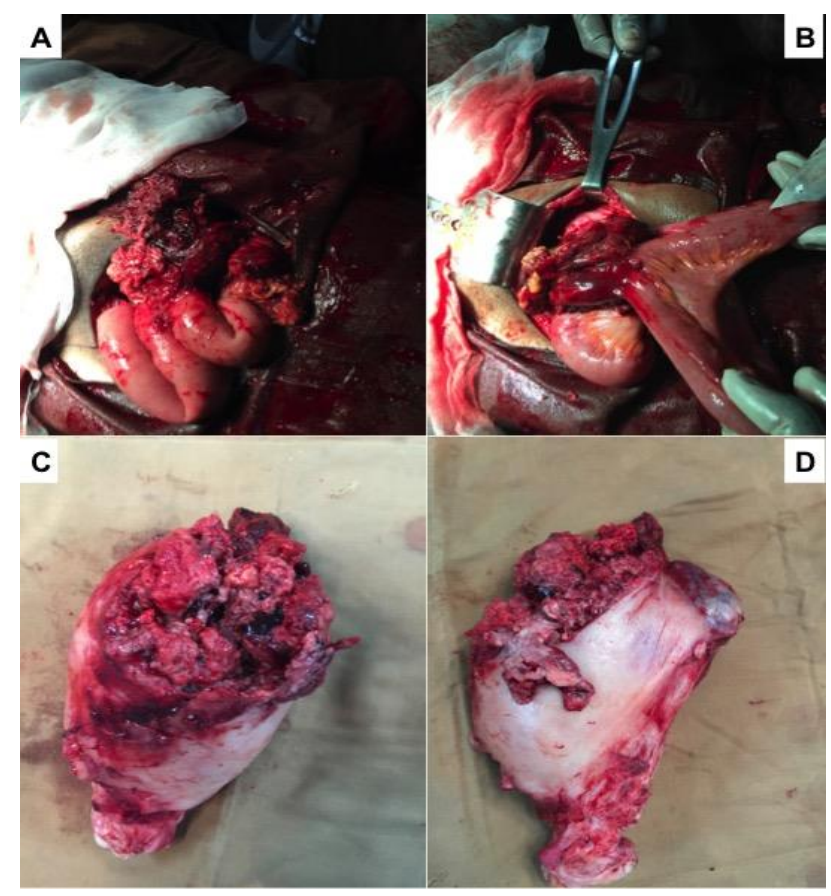

Figure 1: Intraoperative pictures showing intestines joined together with trophoblastic tissues (A and B) and the perforated area with trophoblastic tissue (C and D).

There was no evidence of liver metastasis. Intraoperatively the patient received 2 units of packed cell transfusion. During postoperative period she received 2 more units of blood transfusion and made an uneventful recovery. Chemotherapy was scheduled after healing but parents returned with her to the village when the situation had improved. After three weeks, she was readmitted with cachexia and poor general condition with anaemia, malnutrition and abdominal mass. Her condition did not allow chemotherapy. She died 5 days after.

\section{DISCUSSION}

Gestational choriocarcinoma is a rare malignant tumour with a strong metastatic potential. The incidence of post term choriocarcinoma is approximately 1 in every 20,000-40,000 pregnancies. Fifty per cent of these choriocarcinomas develop after term pregnancies. ${ }^{3}$ Choriocarcinoma is suspected when there is persistent or irregular uterine bleeding following abortion or hydatidiform mole. Rapid growth and haemorrhage make the tumour a surgical emergency; one of these emergent conditions is uterine perforation due to myometrium invasion. These tumours are highly vascular, and it is believed that with the death of the trophoblastic cells, there is little tissue support for the vascular tissue associated with these pregnancies; therefore, intralesional bleeding at the start of chemotherapy may occur, but excessive bleeding is rare. ${ }^{4}$ Invasive mole may perforate uterus through the myometrium resulting in uterine perforation and intraperitoneal bleeding. But uterine perforation due to choriocarcinoma is rare. ${ }^{5}$

Patients with acute abdomen from uterine perforation and shock should be managed aggressively and bleeding focus has to be managed with surgical intervention. A total abdominal hysterectomy is the preferred approach in females especially with family completed. Patients under emergency conditions who are operated with explorative laparotomy due to severe active intra-abdominal bleeding usually require hysterectomy as lifesaving procedure. In Africa, hydatiform mole can often go unnoticed because pathologic confirmation of the diagnosis is not always performed. If a choriocarcinoma occurs after hydatiform mole as in our patient, the diagnosis may be difficult to make if a relationship is not established with the previous molar pregnancy.

Conservative surgery is the preferred approach in females with disease limited to the uterus and who wish to preserve their fertility. ${ }^{6}$ As Goto et al mentioned, hysterectomy is not needed to cure choriocarcinoma. Selective embolization of the major pelvic blood supply to the tumour can be performed by interventional radiology. In patients who are hemodynamically stable, this option should be considered as reported by Bentash et al. ${ }^{4}$ Multi-agent chemotherapy and radiotherapy are used for high-risk, metastatic choriocarcinomas (score $>6) .{ }^{8}$ In our case multi drug regimen (EMACO) was planned to be started in view of high-risk disease.

\section{CONCLUSION}

Choriocarcinoma is a life threatening haemorrhage. In developing countries efforts, must be done in follow up of molar pregnancy and early diagnosis of gestational trophoblastic neoplasia.

\section{Funding: No funding sources \\ Conflict of interest: None declared \\ Ethical approval: Not required}

\section{REFERENCES}

1. Alazzam M, Tidy J, Osborne R, Coleman R, Hancock BW, Lawrie TA. Chemotherapy for resistant or recurrent gestational trophoblastic neoplasia. Cochrane Database Syst Rev 2012.

2. Biscaro A, Braga A, Berkowitz RS. Diagnosis, classification and treatment of gestational trophoblastic neoplasia. Rev Bras Ginecol Obstet. 2015;37(1):42-51. 
3. Lok CA, Ansink AC, Grootfaam D, van der Velden J, Verheijen RH, ten Kate-Booij MJ. Treatment and prognosis of post term choriocarcinoma in The Netherlands. Gynecologic Oncology. 2006;103:698702.

4. Behtash N, Ansari S, Sarvi F. Successful pregnancy after localized resection of perforated uterus in choriocarcinoma and a literature review. Int Immuno J Gynecol Cancer. 2006;16:445-8.

5. Mackenzie F, Mathers A, Kennedy J. Invasive hydatidiform mole presenting as an acute primary haemoperitoneum. $\mathrm{Br} \quad \mathrm{J}$ Obstet Gynecol. 1993;100:953-4.

6. Agarwal M, Kumar R, Pyrbot J, Singh AS. Choriocarcinoma with Uterine Rupture and Shock: A
Rare Case Report. Journal of Clinical and Diagnostic Research. 2015;9(10):ED20-ED1.

7. FIGO Oncology Committee. FIGO staging for gestational trophoblastic neoplasia. Int J Gynaecol Obstet. 2002;77:285-7.

8. Goto S, Ino K, Mitsui T, Kikkawa F, Suzuki T, Nomura S, et al. Survival rates of patients with choriocarcinoma treated with chemotherapy without hysterectomy: effects of anti cancer agents on subsequent births. Gynecol Oncol. 2004;93:529-35.

Cite this article as: Gueye M, Gueye MDN, Thiam $\mathrm{O}$, Toure Y, Cisse M, Wade M et al.

Choriocarcinoma with uterine rupture presenting as acute haemoperitoneum and shock. Int J Reprod Contracept Obstet Gynecol 2017;6:1141-3. 